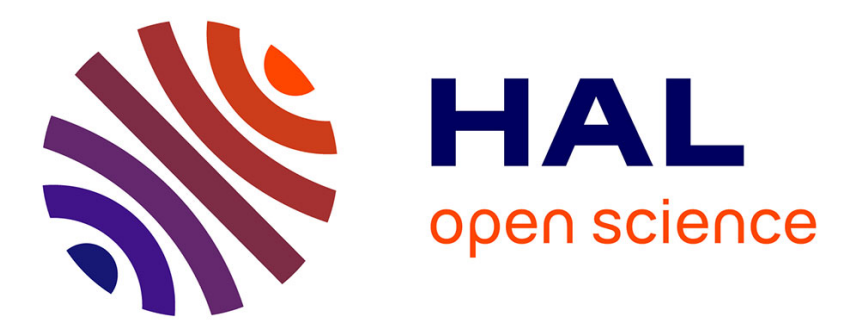

\title{
A study on tracking position control of an electropneumatic system using backstepping design
}

Mohamed Smaoui, Xavier Brun, Daniel Thomasset

\section{To cite this version:}

Mohamed Smaoui, Xavier Brun, Daniel Thomasset. A study on tracking position control of an electropneumatic system using backstepping design. Control Engineering Practice, 2006, 14 (8), pp.923933. 10.1016/j.conengprac.2005.05.003 . hal-00140642

\section{HAL Id: hal-00140642 https://hal.science/hal-00140642}

Submitted on 1 Apr 2019

HAL is a multi-disciplinary open access archive for the deposit and dissemination of scientific research documents, whether they are published or not. The documents may come from teaching and research institutions in France or abroad, or from public or private research centers.
L'archive ouverte pluridisciplinaire HAL, est destinée au dépôt et à la diffusion de documents scientifiques de niveau recherche, publiés ou non, émanant des établissements d'enseignement et de recherche français ou étrangers, des laboratoires publics ou privés. 


\title{
A study on tracking position control of an electropneumatic system using backstepping design
}

\author{
M. Smaoui, X. Brun, D. Thomasset \\ Laboratoire d'Automatique Industrielle - INSA de Lyon \\ http://www-lai.insa-lyon.fr/ \\ Bât Antoine de SAINT-EXUPERY, 25, avenue Jean Capelle \\ 69621Villeurbanne Cedex, France \\ Tel: (33) 472438881 \\ Fax: (33) 472438535 \\ E-mail address: mohamed.smaoui@insa-lyon.fr
}

\begin{abstract}
As an important driving element, the pneumatic cylinder is widely used in industrial applications because of its reliable, cheap and excellent performance in an industrial servo system. However, along with the development of control technology, the requirement for control precision gets higher and higher. In many cases, in order to achieve the satisfied control performance, the effects of nonlinear factors contained is considered in the plant. Backstepping is one of these nonlinear control techniques which has attracted a great deal of research interest in recent years. It is mainly applicable to strict-feedback system.

This paper presents a new form of backstepping controller for an electropneumatic system. Notice that the model of this system is not under strict-feedback form. Then, a modified methodology is proposed, synthesized and implemented on an experimental test bench. Experimental results are presented and discussed.
\end{abstract}

Keywords: Nonlinear control; Pneumatic systems; Backstepping control; Experimental results.

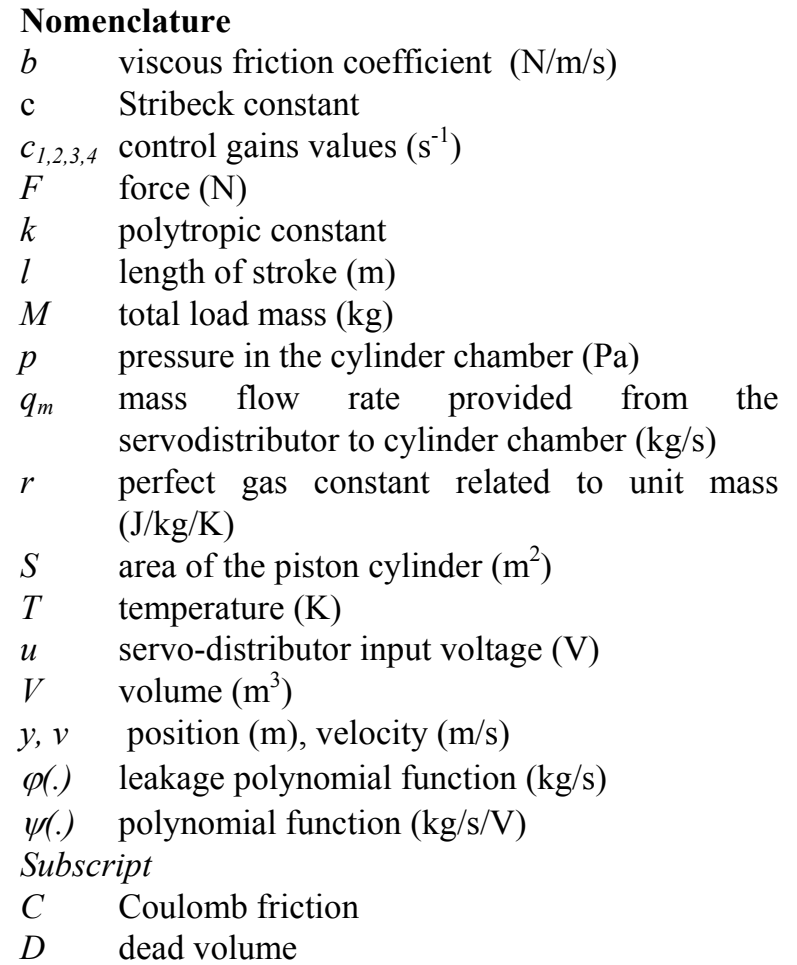

$\begin{array}{ll}d & \text { desired } \\ e & \text { equilibrium } \\ \text { ext } & \text { external } \\ f & \text { dry friction } \\ N & \text { chamber } \mathrm{N} \\ \mathrm{P} & \text { chamber } \mathrm{P} \\ S & \text { supply } \\ \mathrm{S} & \text { stiction friction }\end{array}$

\section{Introduction}

Pneumatic cylinder systems have the potential to provide high output power to weight and size ratios at a relatively low cost. Adding to their simple structure, easy maintenance, and low component cost, pneumatic actuators are one of the most common type of industry actuators. However the complexity of the electropneumatic systems and the important range of control laws are a real industrial problem where the target is to choose the best strategy for a given application.

The traditional and widely used approach to the control of electropneumatic systems is a fixed gain 
linear controller, based on the local linearization of the nonlinear dynamics about a nominal operating point (Brun et al., 1999a). This method relies on the key assumption of small range operation for the linear model to be valid. When the required operation range is large, the linear controller is likely to perform poorly or to be unstable, because of the limitation of the linear feedback controller's tolerance for the adverse effect of the nonlinearities.

When a fixed gain linear controller can not satisfy the control requirement, it is natural to investigate other controllers. In recent years, research efforts have been directed toward meeting this requirement. Most of them are feedback linearization (Kimura et al., 1997), fuzzy control algorithms (Parnichkun and Ngaecharoenkul, 2001), adaptive control, (Li et al., 1997), sliding mode control (Bouri, \& Thomasset, 2001), and robust control (Mattei, 2001).

Backstepping (Kanellakopoulos et al., 1991; Freeman \& Kokotović, 1993) is one of these advanced control techniques which has attracted a great deal of research interest in recent years. It is mainly applicable to systems having a cascaded or triangular structure. The central idea of the approach is to recursively design controllers for subsystems in the structure and "step back" the feedback signals towards the control input. This differs from the conventional feedback linearization in that it offers a more flexible way of dealing with uncertainties. Using the Lyapunov functions, their impact on the system can be analysed so that stabilizing and thus in a sense useful, nonlinearities may be kept while harmful nonlinearities can be cancelled or dominated by the control signal. For this, backstepping technique is chosen to synthesize a controller for the electropneumatic system.

This paper is organized as follows: section 2 describes the model of the electropneumatic system. Section 3 presents backstepping in an informal setting. Then, the backstepping control law for the electropneumatic system is derived in detail. Section 4 is devoted to the experimental results to prove the effectiveness of the proposed backstepping method. Section 5 concludes the paper.

\section{Electropneumatic system modeling for control synthesis}

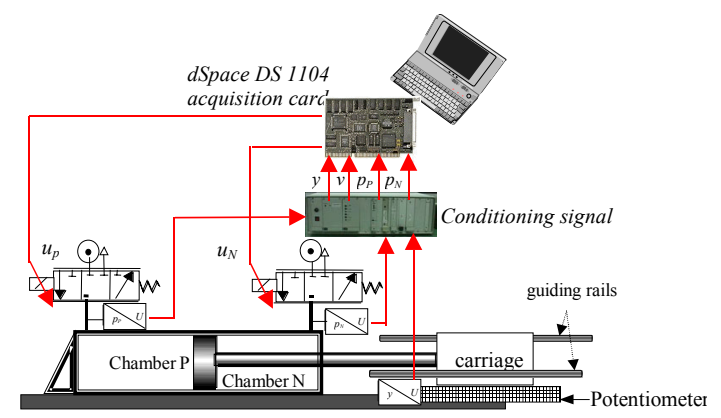

Fig. 1. The electropneumatic system
The electropneumatic system (Fig. 1) uses the following structure: two three-way proportional servodistributors/ actuator/ mass in translation. The actuator under consideration is an in-line electropneumatic cylinder using a simple rod. The rod is connected to one side of a carriage and drives an inertial load on guiding rails. The total moving mass is equal to $17 \mathrm{~kg}$. Table 1 shows the specifications of the pneumatic actuator.

Table 1: Specifications of the pneumatic actuator

\begin{tabular}{|c|c|}
\hline Diameter of piston & $3.210^{-2} \mathrm{~m}$ \\
\hline Diameter of rod & $210^{-2} \mathrm{~m}$ \\
\hline Length of stroke & $0.5 \mathrm{~m}$ \\
\hline Dead volume $\mathrm{V}_{\mathrm{DP}}$ & $10^{-5} \mathrm{~m}^{3}$ \\
\hline Dead volume $\mathrm{V}_{\mathrm{DN}}$ & $1.210^{-5} \mathrm{~m}^{3}$ \\
\hline
\end{tabular}

The electropneumatic system model can be obtained using three physical laws: the mass flow rate through a restriction, the pressure behavior in a chamber with variable volume and the fundamental mechanical equation.

The two servodistributors are the same. This component has been developed in collaboration with Asco Joucomatic and LAI laboratory (Sesmat et al., 1996). This product is an electropneumatic flow valve and consists of a matching spool-sleeve assembly and a proportional magnet directly controlling the movement of the spool against a spring. The spool is controlled in position by means of a position sensor. On the contrary of many other valve designs used in automotive or railway applications or in pneumatic circuits, the spool-sleeve technology has been preferred to the poppet technology. This means that pressure accuracy around zero opening has been set to the detriment of leakage. So this technology leads to characteristics without dead zone. In our case, the bandwidth of the Servotronic Joucomatic servodistributor and the actuator are respectively about $200 \mathrm{~Hz}$ and $2.4 \mathrm{~Hz}$. Using the singular perturbation theory, the dynamic of the servodistributors are neglected and there models can be reduced to a static one described by two relationships $q_{m} P\left(u_{P}, p_{P}\right)$ and $q_{m}{ }\left(u_{N}, p_{N}\right)$ between the mass flow rates $q_{m} P$ and $q_{m} N$, the input voltages $u_{P}$ and $u_{N}$, and the output pressures $p_{P}$ and $p_{N}$. The pressure evolution law in a chamber with variable volume is obtained assuming the following assumptions (Shearer, 1956): air is a perfect gas and its kinetic energy is negligible, the pressure and the temperature are homogeneous in each chamber, the process is polytropic and characterized by coefficient $\mathrm{k}$. Moreover, the electropneumatic system model is obtained by combining all the previous relations and assuming that the temperature 
variation is negligible with respect to average and equal to the supply temperature. So the following relation gives the model of the above system :

$$
\left\{\begin{array}{l}
\frac{d y}{d t}=v \\
\frac{d v}{d t}=\frac{1}{M}\left[S_{P} p_{P}-S_{N} p_{N}-b v-F_{f}(v)-F_{e x t}\right] \\
\frac{d p_{P}}{d t}=\frac{k r T}{V_{P}(y)}\left[q_{m}\left(u_{P}, p_{P}\right)-\frac{S_{P}}{r T} p_{P} v\right] \\
\frac{d p_{N}}{d t}=\frac{k r T}{V_{N}(y)}\left[q_{m}\left(u_{N}, p_{N}\right)+\frac{S_{N}}{r T} p_{N} v\right]
\end{array}\right.
$$

Where: $\left\{\begin{array}{l}V_{P}(y)=V_{P}(0)+S_{P} y \\ V_{N}(y)=V_{N}(0)-S_{N} y\end{array}\right.$ with $\left\{\begin{array}{l}V_{p}(0)=V_{D P}+S_{P} \frac{l}{2} \\ V_{N}(0)=V_{D N}+S_{N} \frac{l}{2}\end{array}\right.$

are the piping volumes of the chambers for the zero position and $V_{D(\operatorname{Por} N)}$ are dead volumes present on each extremities of the cylinder.

The two first equations in (1) describe the mechanical part. They are obtained using the fundamental mechanical equation applied to the moving part. The term $F_{f}(v)$ represents the dry friction forces which act on the moving part in presence of viscous friction $(b v) . F_{e x t}$ is an external force only due to atmospheric pressure. The external force represent $7 \%$ of the maximum force that the electropneumatic system can be delivered, so it is significant to take it into account. The two last equations in (1) concern the pneumatic part of the system.

Friction are inevitable in many mechanical systems and there effects have been demonstrated by a number of researchers (Armstrong-Helouvry et al.,1994). It is mostly noticeable at low velocity because of the extremely high gain at velocities near zero, due to contact inside the cylinder (between seal and metal) or in moving part (here a carriage) along the guiding rails. In many applications concerning electropneumatic system, the control law is synthesized with neglected dry friction (Parnichkun \& Ngaecharoenkul, 2001; Bouri, \& Thomasset, 2001). One of the improvement and interest of this paper is due to taking account of all dry friction. In this approach, mathematical non linear model will be adopted using the well known Tustin friction model (Tustin, 1947) given by relation (2)

$$
F_{f}(v)=\left[F_{s}+\left(F_{s}-F_{C}\right) \exp (-c|v|)\right] \operatorname{sgn}(v)
$$

This conventional model is generally accepted (Armstrong-Helouvry et al., 1994).

Fig 2 shows the results of the friction model for low velocities. Outside of the small velocity region shown in Fig.2, the dry friction is dominated by the constant Coulomb friction value.

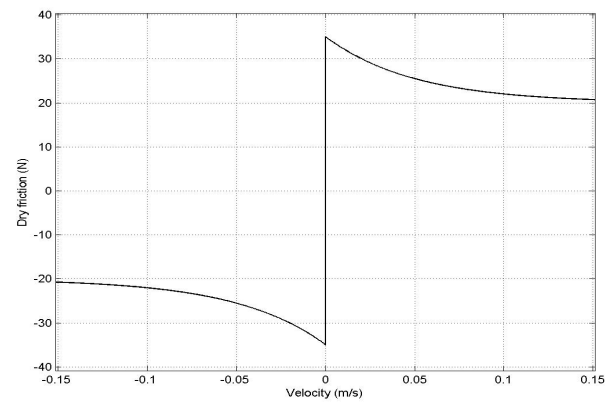

Fig. 2. Dry friction model

The main difficulty for model (1) is to know the mass flow rates $q_{m} P$ and $q_{m} N$. This model is issue of experimental measurement (Sesmat et al., 1996) and therefore a mathematical model for a static flow stage has been obtained from a polynomial approximation affine in control. Indeed, in order to approximate the flow stage characteristics, the authors in (Belgharbi et al., 1999) have developed analytical model for both simulation and control purposes such as:

$q_{m}(u, p)=\varphi(p)+\psi(p, \operatorname{sgn}(u)) u$

$\varphi(p)$ in (3) is a polynomial function of the pressure whose evolution corresponds to the mass flow rate leakage, it is identical for all input control value. $\psi(p, \operatorname{sgn}(u))$ is a polynomial function of the pressure and it is a function of the input control sgn because the behavior of the mass flow rate characteristics is clearly different for the inlet $(u>0)$ and the exhaust $(u<0)$. The polynomial function $\varphi(p), \psi(p, u>0), \psi(p, u<0)$ have degrees equal to five. The maximum mass flow rate error between static measurement and polynomial approximation il less then $10 \%$

From the equation (3) the nonlinear affine model is then given by the following equation:

$\left\{\begin{array}{l}\frac{d y}{d t}=v \\ \frac{d v}{d t}=\frac{1}{M}\left[S_{P} p_{P}-S_{N} p_{N}-b v-F_{f}(v)-F_{e x t}\right] \\ \frac{d p_{P}}{d t}=\frac{k r T}{V_{P}(y)}\left[\varphi\left(p_{P}\right)-\frac{S_{P}}{r T} p_{P} v\right]+\frac{k r T}{V_{P}(y)} \psi\left(p_{P}, \operatorname{sgn}\left(u_{P}\right)\right) u_{P} \\ \frac{d p_{N}}{d t}=\frac{k r T}{V_{N}(y)}\left[\varphi\left(p_{N}\right)+\frac{S_{N}}{r T} p_{N} v\right]+\frac{k r T}{V_{N}(y)} \psi\left(p_{N}, \operatorname{sgn}\left(u_{N}\right)\right) u_{N}\end{array}\right.$

The dry friction model (2) cannot be used for the synthesis of the backstepping control law because this model contains the function $\operatorname{sgn}(v)$ which makes it non analytical. This is why this function has been approximated by the analytical function (5). This method is classical and its performance has been always be proved (Leine et al., 1998; Kim et al., 2003).

$\operatorname{sgn}(v)=\frac{2}{\pi} \operatorname{atan}(\gamma \cdot v)$ 
$\gamma$ was adjusted in order to carry out a good approximation.

Nowadays, several algorithms for position control of an pneumatic systems are proposed. In (Wang et al., 1999a), a study on tracking position control of a pneumatic system is presented. The authors shows that acceleration feedback plays a very important role in the stabilisation of servopneumatic actuator systems.

Two algorithms based on a modified PID controller are proposed in (Wang et al., 1999b) and a PID optimal controller is proposed by (Shih et al., 1995).

A sliding mode controller using an integral switching surface is proposed in (Bouri \& Thomasset, 2001). High accuracy and robustness with respect to various internal and external disturbances are achieved. However, specific drawback presented by the classical sliding mode techniques is the chattering phenomenon.

In (Parnichkun \& Ngaecharoenkul, 2001), a hybrid of fuzzy and PID control algorithm is proposed for point to point displacement. The control algorithm is separated into two parts, fuzzy control and PID control. Fuzzy control is used to control the piston when the piston locates far away from the target position. PID control is applied when the position is near the desired. The results from the proposed algorithm were better than P, PI, PD and PID controls.

Several others control strategies for pneumatic systems such as feedback linearization (Kimura et al., 1997; Brun et al., 2002) and robust control (Mattei, 2001) are used.

In this paper, a study on tracking position control using backstepping design is proposed. The main features of the control strategy developed in the paper are:

- proving the global stability of the closed loop system

- respecting a good accuracy in term of position tracking for a desired trajectory

\section{Backstepping controller for an electropneumatic system}

\subsection{Backstepping design}

Backstepping is a recursive procedure, which allows deriving control law for a nonlinear system, associated with appropriate Lyapunov function, which guaranties stability.

Classes of systems, for which this procedure works, are given in (Alleyne, \& Liu, 2000; Khalil, 2001). One of such classes is so called strict-feedback system (6).

$$
\left\{\begin{array}{l}
\dot{x}=f_{0}(x)+g_{0}(x) z_{1} \\
\dot{z}_{1}=f_{1}\left(x, z_{1}\right)+g_{1}\left(x, z_{1}\right) z_{2} \\
\dot{z}_{2}=f_{2}\left(x, z_{1}, z_{2}\right)+g_{2}\left(x, z_{1}, z_{2}\right) z_{3} \\
\quad \vdots \\
\dot{z}_{n-1}=f_{n-1}\left(x, z_{1}, z_{2}, \ldots, z_{n-1}\right)+g_{n-1}\left(x, z_{1}, z_{2}, \ldots, z_{n-1}\right) z_{n} \\
\dot{z}_{n}=f_{n}\left(x, z_{1}, z_{2}, \ldots, z_{n}\right)+g_{n}\left(x, z_{1}, z_{2}, \ldots, z_{n}\right) u
\end{array}\right.
$$

Where $x \in \mathfrak{R}^{\mathrm{n}}, z_{1}$ to $z_{n}$ are scalars, and $f_{0}$ to $f_{n}$ vanish at the origin. The reason for referring to such systems as "strict feedback" is that the nonlinearities $f_{i}$ and $g_{i}$ in the $\dot{z}_{\mathrm{i}}$-equation $(i=1, \ldots, n)$ depend only on $x, z_{1}, \ldots$, $z_{i+1}$; that is, on the state variables that are "feed back" (see Fig. 3).

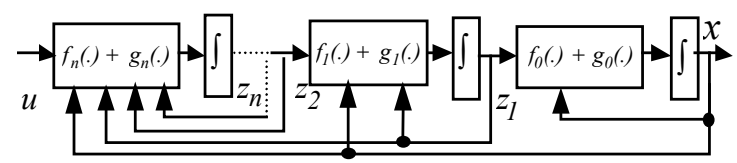

Fig. 3. Diagram of strict feedback system

One assume that :

$g_{i}\left(x, z_{1}, \ldots, z_{i}\right) \neq 0, \quad 1 \leq i \leq n$

over the domain of interest. The recursive procedure starts with the system (8).

$\dot{x}=f_{0}(x)+g_{0}(x) z_{1}$

where $z_{1}$ is viewed as the control input. One assume that it is possible to determine a stabilizing state feedback control law $z_{1}=\alpha_{0}(x)$, with $\alpha_{0}(0)=0$, and a Lyapunov function $V_{0}(x)$ such that

$\frac{\partial V_{0}}{\partial x}\left[f_{0}(x)+g_{0}(x) \alpha_{0}(x)\right] \leq-W(x)$

over the domain of interest for some positive definite function $W(x)$. In many applications of backstepping, the variable $x$ is scalar, which simplifies this stabilization problem.

However, $z_{l}$ is not available for control. The key property of backstepping is that it offers a constructive way of forwarding the unattainable control $z_{1}=\alpha_{0}(x)$ to a new virtual control law $z_{2}=$ $\alpha_{1}\left(x, z_{1}\right)$. If this could be satisfied, $x$ and $z_{1}$ would be successfully brought back to the origin. This recursive procedure is repeated until the actual control variable $u$ is reached after $n$ steps, whereby a stabilizing control law, $u=\alpha_{n}\left(x, z_{1}, \ldots, z_{n}\right)$, is established.

Along with the control law, a Lyapunov function is constructed, proving the global stability of the closed loop system. Indeed, at the $i$-th step a $V_{i-1}$ Lyapunov function is known, which stabilize $i$ equations. It is associated with a virtual control law $\alpha_{i-1}$. This new control is evaluated in order to make the derivative of the Lyapunov function negative (Krstić et al., 1995).

\subsection{Control synthesis}

The system use two three-way proportional 
servodistributors. Generally (Brun et al., 2002), it is supposed that these two servodistributors are equivalent to one five-way proportional servodistributor when they are controlled with input of opposite signs. In this case, a monovariable position control law can be established. However, the validity of the control law depends on the stability of the unobservable subsystem, which is onedimensional. It is very difficult to obtain results about the global stability of the zero dynamics (Bouri, \& Thomasset, 2001).

With the system of two three-way servodistributors, it is possible to prove the global stability. Indeed, the system is rewritten in an appropriate form. In fact, the pneumatic subsystem (third and fourth state equations in model (4)) is transformed in two pure integrators with using feedback linearization.

One note that $\psi(p, \operatorname{sgn}(u)) \neq 0$ over the physical domain, as the pressures are limited by the exhaust pressure $(1 \mathrm{bar})$ and the supply pressure $(7 \mathrm{bar})$ (see Fig.4).

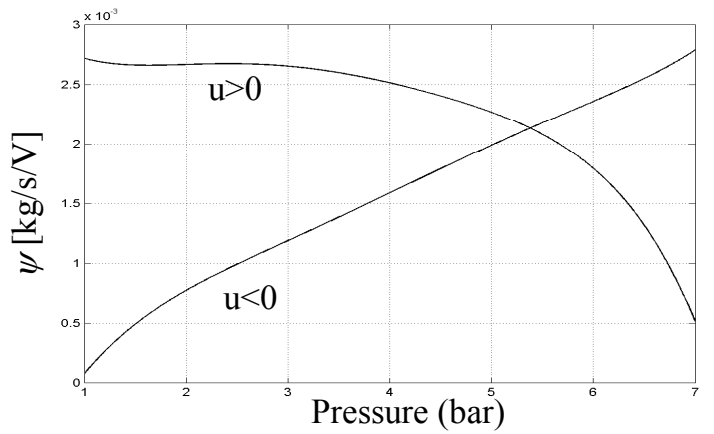

Fig. 4. The function $\psi(p, \operatorname{sgn}(u))$

This is lead to propose the input transformation :

$$
\left\{\begin{array}{l}
u_{P}=\frac{1}{S_{P} \frac{k r T}{V_{P}(y)} \psi\left(p_{P}, \operatorname{sgn}\left(u_{P}\right)\right)}\left[u_{1}-S_{P} \frac{k r T}{V_{P}(y)}\left(\varphi\left(p_{P}\right)-\frac{S_{P}}{r T} P_{P} v\right)\right] \\
u_{N}=\frac{1}{S_{N} \frac{k r T}{V_{N}(y)} \psi\left(p_{N}, \operatorname{sgn}\left(u_{N}\right)\right)}\left[u_{2}-S_{N} \frac{k r T}{V_{N}(y)}\left(\varphi\left(p_{N}\right)+\frac{S_{N}}{r T} p_{N} v\right)\right]
\end{array}\right.
$$

By using (10), the pneumatic subsystem is transformed into two pure integrators (see Fig. 5). So nonlinearities due to the mass flow rate delivered by the servo-distributor and due to compressibility of air are compensated by this linearization which has proved itself experimentally (Sesmat \& Scavarda, 1996).

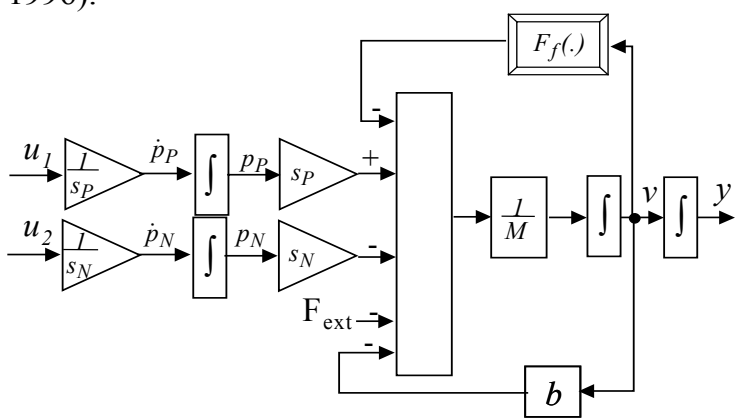

Fig. 5. Block diagram of model after feedback linearization
The nonlinear model of the system in Fig. 1 has now the following form, where $u_{1}$ and $u_{2}$ are the two inputs

$$
\left\{\begin{array}{l}
\frac{d y}{d t}=v \\
\frac{d v}{d t}=\frac{1}{M}\left[S_{P} p_{P}-S_{N} p_{N}-b v-F_{f}(v)-F_{\text {ext }}\right] \\
\frac{d p_{P}}{d t}=\frac{u_{1}}{S_{P}} \\
\frac{d p_{N}}{d t}=\frac{u_{2}}{S_{N}}
\end{array}\right.
$$

By using the coordinate transformation:

$$
\left\{\begin{array}{l}
x_{1}=y \\
x_{2}=v \\
x_{3}=S_{P}\left(p_{P}-p_{p}^{e}\right) \\
x_{4}=S_{N}\left(p_{N}-p_{N}^{e}\right)
\end{array}\right.
$$

At the equilibrium $F_{e x t}=S_{P} p_{P}^{e}-S_{N} p_{N}^{e}, v^{e}=0$, and $F_{f}(0)=0$. So, the nonlinear model has the form given by equation (13)

$$
\left\{\begin{array}{l}
\dot{x}_{1}=x_{2} \\
\dot{x}_{2}=\frac{1}{M}\left[x_{3}-x_{4}-b x_{2}-F_{f}\left(x_{2}\right)\right] \\
\dot{x}_{3}=u_{1} \\
\dot{x}_{4}=u_{2}
\end{array}\right.
$$

This system has two inputs $u_{1}$ and $u_{2}$. The objective is to find the two control laws in order to track a desired position $x_{1 d}$. The methodology proposed to applied backstepping is as follows:

Step1: Let $z_{1}$ be the deviation of $x_{1}$ from its desired value:

$z_{1}=x_{1}-x_{1 d}$

The derivative of the position error is computed as:

$\dot{z}_{1}=x_{2}-x_{2 d}$

with $x_{2}$ viewed as the input. Now, the objective is to design a feedback control $x_{2}=\alpha\left(z_{1}, x_{2 d}\right)$ in order to stabilize the error $z_{1}=0$. with:

$x_{2}=\alpha\left(z_{1}, x_{2 d}\right)=-c_{1} z_{1}+x_{2 d}$

with $c_{1}\left[s^{-1}\right]$ a strictly positive constant, the closedloop subsystem becomes:

$\dot{z}_{1}=-c_{1} z_{1}$

The control law (17) satisfies the requirement. Indeed, with a Lyapunov function $V\left(z_{1}\right)=\frac{1}{2} z_{1}^{2}$ (Krstić et al., 1995), that is, $\dot{V}\left(z_{1}\right)=-c_{1} z_{1}^{2}<0$.

Step 2: This is a key step in the design procedure. Indeed, since $x_{2}$ is not actually a control but, rather, a 
state variable, the following change of variables is introduced:

$$
z_{2}=x_{2}-\alpha\left(z_{1}, x_{2 d}\right)=x_{2}-x_{2 d}+c_{1} z_{1}
$$

which represent the difference between the virtual control $x_{2}$ and the stabilizing function. In the new coordinates $\left(z_{1}, z_{2}\right)$ the system is expressed as

$$
\left\{\begin{aligned}
\dot{z}_{1} & =z_{2}-c_{1} z_{1} \\
\dot{z}_{2} & =\frac{1}{M}\left[x_{3}-x_{4}-b\left(z_{2}-c_{1} z_{1}+x_{2 d}\right)\right. \\
& \left.-F_{f}\left(z_{2}-c_{1} z_{1}+x_{2 d}\right)\right]+c_{1}\left(z_{2}-c_{1} z_{1}\right)-\dot{x}_{2 d}
\end{aligned}\right.
$$

Along with the controller design, a Lyapunov function is constructed, proving the stability of the closed loop subsystem. Let us try to construct it by augmenting $V\left(z_{1}\right)$ with a quadratic term in the error variable $z_{2}$ :

$V\left(z_{1}, z_{2}\right)=\frac{1}{2} z_{1}^{2}+\frac{1}{2} z_{2}^{2}=V\left(z_{1}\right)+\frac{1}{2} z_{2}^{2}$

The derivative of $V\left(z_{1}, z_{2}\right)$ along the solution of (19) is computed as:

$$
\begin{aligned}
& \dot{V}\left(z_{1}, z_{2}\right)=z_{1} \dot{z}_{1}+z_{2} \dot{z}_{2} \\
& =\dot{V}\left(z_{1}\right)+z_{2}\left(z_{1}+\frac{1}{M}\left[x_{3}-x_{4}-b\left(z_{2}-c_{1} z_{1}+x_{2 d}\right)\right.\right. \\
& \left.\left.-F_{f}\left(z_{2}-c_{1} z_{1}+x_{2 d}\right)\right]+c_{1}\left(z_{2}-c_{1} z_{1}\right)-\dot{x}_{2 d}\right)
\end{aligned}
$$

As always, at the second step, $\dot{V}\left(z_{1}, z_{2}\right)$ must be an explicit function of the variable $x_{3}$ and the objective is to design $x_{3}$ to satisfy the negativity of the Lyapunov function. This is why the system must have a so called strict-feedback form (see equation (6)). However, the electropneumatic actuator model is not in the required form. Indeed, the state variables $x_{3}$ and $x_{4}$ appear at the same step. Thus the idea is to consider $x_{3}-x_{4}$ as a virtual control

$$
\begin{aligned}
x_{3}-x_{4}= & F_{f}\left(z_{2}-c_{1} z_{1}+x_{2 d}\right)-\left(M-M c_{1}^{2}+b c_{1}\right) z_{1} \\
& -\left(M c_{1}+M c_{2}-b\right) z_{2}+b x_{2 d}+M \dot{x}_{2 d}
\end{aligned}
$$

and then to determine the values of $x_{3}$ and $x_{4}$ as follows:

$$
\begin{aligned}
x_{3}= & \lambda\left[F_{f}\left(z_{2}-c_{1} z_{1}\right)-\left(M-M c_{1}^{2}+b c_{1}\right) z_{1}\right. \\
& \left.-\left(M c_{1}+M c_{2}-b\right) z_{2}+b x_{2 d}+M \dot{x}_{2 d}\right] \\
= & \alpha_{1}\left(z_{1}, z_{2}, x_{2 d}, \dot{x}_{2 d}\right) \\
x_{4}= & (\lambda-1)\left[F_{f}\left(z_{2}-c_{1} z_{1}\right)-\left(M-M c_{1}^{2}+b c_{1}\right) z_{1}\right. \\
& \left.-\left(M c_{1}+M c_{2}-b\right) z_{2}+b x_{2 d}+M \dot{x}_{2 d}\right] \\
= & \alpha_{2}\left(z_{1}, z_{2}, x_{2 d}, \dot{x}_{2 d}\right)
\end{aligned}
$$

Where $\lambda$ is a tune parameter with $0 \leq \lambda \leq 1$. This ensures the negativity of the Lyapunov function.

$$
\dot{V}\left(z_{1}, z_{2}\right)=\dot{V}\left(z_{1}\right)-c_{2} z_{2}^{2}=-c_{1} z_{1}^{2}-c_{2} z_{2}^{2}<0
$$

for some $c_{2}\left[\mathrm{~s}^{-1}\right]>0$

Step 3: For this stage, there is a difference compared to classic backstepping described in section 3. Two errors variables are created at the same step, as described in equation. (25): The force error imposed in chamber $P$ and the force error in chamber $N$

$\left\{\begin{array}{l}z_{3}=x_{3}-\alpha_{1}\left(z_{1}, z_{2}, x_{2 d}, \dot{x}_{2 d}\right) \\ z_{4}=x_{4}-\alpha_{2}\left(z_{1}, z_{2}, x_{2 d}, \dot{x}_{2 d}\right)\end{array}\right.$

In the new coordinates $\left(z_{1}, z_{2}, z_{3}, z_{4}\right)$ the system is expressed as

$\left\{\begin{array}{l}\dot{z}_{1}=z_{2}-c_{1} z_{1} \\ \dot{z}_{2}=\frac{1}{M}\left(z_{3}-z_{4}\right)-z_{1}-c_{2} z_{2} \\ \dot{z}_{3}=u_{1}-\dot{\alpha}_{1}\left(z_{1}, z_{2}, x_{2 d}, \dot{x}_{2 d}\right) \\ \dot{z}_{4}=u_{2}-\dot{\alpha}_{2}\left(z_{1}, z_{2}, x_{2 d}, \dot{x}_{2 d}\right)\end{array}\right.$

Let us now try to construct a Lyapunov function control by augmenting $V\left(z_{1}, z_{2}\right)$ with two quadratic term in the error variables $z_{3}$ and $z_{4}$ :

$V\left(z_{1}, z_{2}, z_{3}, z_{4}\right)=V\left(z_{1}, z_{2}\right)+\frac{1}{2} z_{3}^{2}+\frac{1}{2} z_{4}^{2}$

Taking

$u_{1}=\dot{\alpha}_{1}\left(z_{1}, z_{2}, x_{2 d}, \dot{x}_{2 d}\right)-\frac{z_{2}}{M}-c_{3} z_{3}$

and

$u_{2}=\dot{\alpha}_{2}\left(z_{1}, z_{2}, x_{2 d}, \dot{x}_{2 d}\right)+\frac{z_{2}}{M}-c_{4} z_{4}$

So the derivative of the Lyapunov function becomes:

$$
\begin{aligned}
& \dot{V}\left(z_{1}, z_{2}, z_{3}, z_{4}\right)=\dot{V}\left(z_{1}, z_{2}\right)-c_{3} z_{3}^{2}-c_{4} z_{4}^{2} \\
& =-c_{1} z_{1}^{2}-c_{2} z_{2}^{2}-c_{3} z_{3}^{2}-c_{4} z_{4}^{2}
\end{aligned}
$$

Using the Lasalle-Yoshizawa theorem (Krstić et al., 1995), Hence, the origin is globally asymptotically stable. Fig. 6 shows the block diagram of the overall control system comprising the pressure feedback linearization controller and the backstepping controller.

\section{Experimental results}

Experiment results are provided here to demonstrate the effectiveness of the backstepping controller. Indeed, the proposed controller was implemented using a dSpace DS1104 controller board with a dedicated digital signal processor. The sensed signals, all analog, were run through the signal conditioning unit before being read by the 16 bits A/D. The sample time is equal to $1 m s$

There are two ways to obtain velocity feedback, namely, using a sensor to measure velocity or using position feedback information to generate velocity signals. To reduce the cost of the system, the velocity cylinder is determined by analog differentiating and 


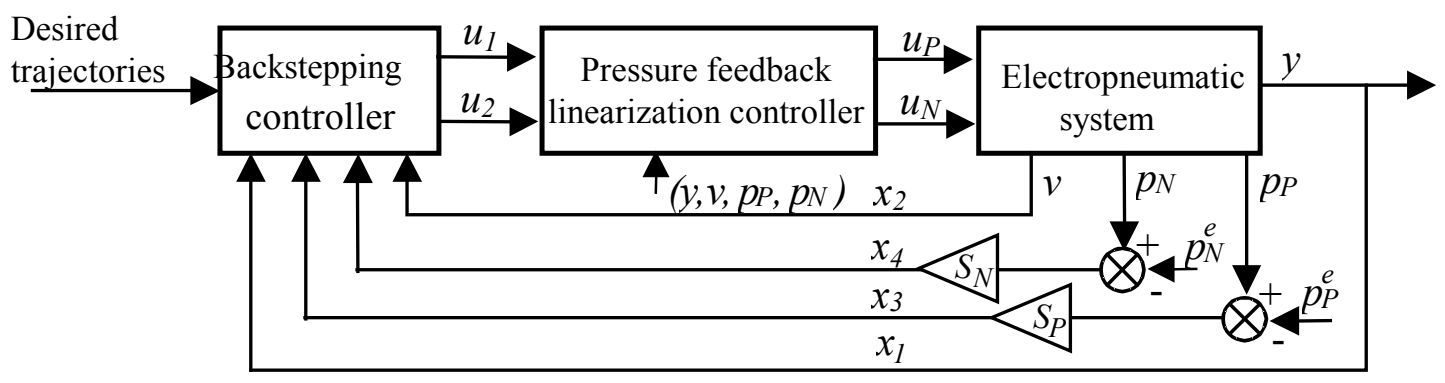

Fig. 6. Block diagram of the proposed controller

low-pass filtering the output of the position. So, the control law is implemented by using three sensors: a position sensor and two pressures sensors.

The position sensor is a NovoTECHNIK, model TLH500. It precision and repeatability is equal to $10 \mu \mathrm{m}$ and it linearity is $0.05 \%$. The precision of the two pressure is equal to $700 \mathrm{~Pa}(0.1 \%)$ and it combined non linearity and hysteresis is equal to $\pm 0.1 \%$.

The aim of the control law is to respect a good accuracy in term of position tracking for a desired trajectory defined by a fifth order polynomial function (see Fig. 7). The amplitude of displacement is equal to $50 \%$ of the total stroke around the central position. The maximum desired velocity is equal to $0.60 \mathrm{~m} / \mathrm{s}$. The test have been made several times in order to see the repeatability of the experimental results.

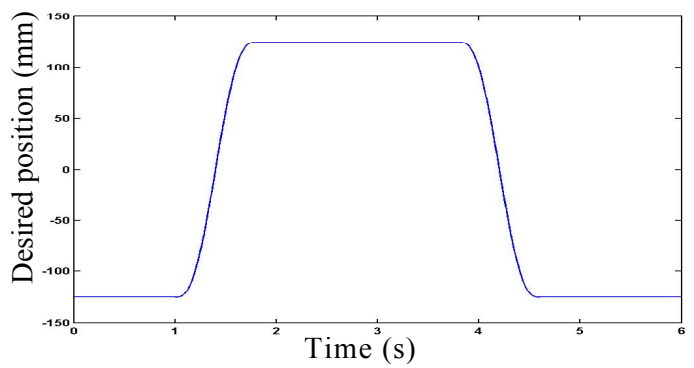

Fig. 7. Desired position (mm)

Firstly, the control gains are chosen small: $c_{1}=40$, $c_{2}=20, c_{3}=12, c_{4}=14$ and $\lambda=0.5$. Fig. 8 show the position error. In static stage, the mean position error is about $100 \mu \mathrm{m}$. In dynamic stage, the maximum position tracking error is about $4.85 \mathrm{~mm}$ which is less then $2 \%$ of the total displacement.

In (Parnichkun \& Ngaecharoenkul, 2001), a hybrid of fuzzy and PID control algorithm is proposed for point to point displacement. In this case the steady state error is about $3.5 \mathrm{~mm}$ (the total displacement is equal to $200 \mathrm{~mm}$ ). A PID controller augmented with friction compensation using neural network is presented in (Lee et al. 2002). A sinusoids with magnitudes of $70 \mathrm{~mm}$ and frequency of $0.2 \mathrm{~Hz}$ were used as reference inputs. In this case, the maximum position error is about $8.1 \mathrm{~mm}$. So, from this point of view, the obtained results with the backstepping controller is more significant.

Fig. 9 and Fig. 10 shows the evolution of the pressure in each chamber $P$ and $N$. The pressures evolutions are smooth and without high frequency excitation.

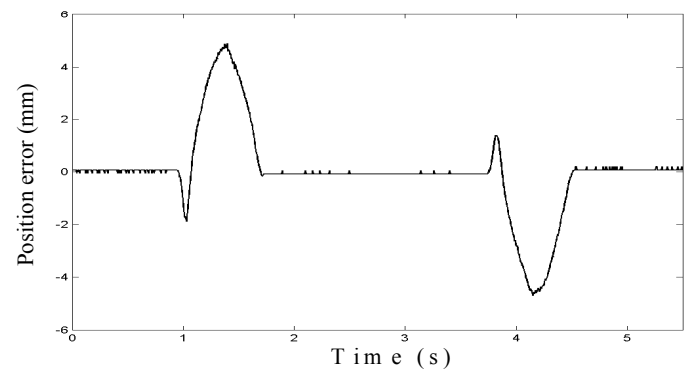

Fig. 8. Position error (mm)

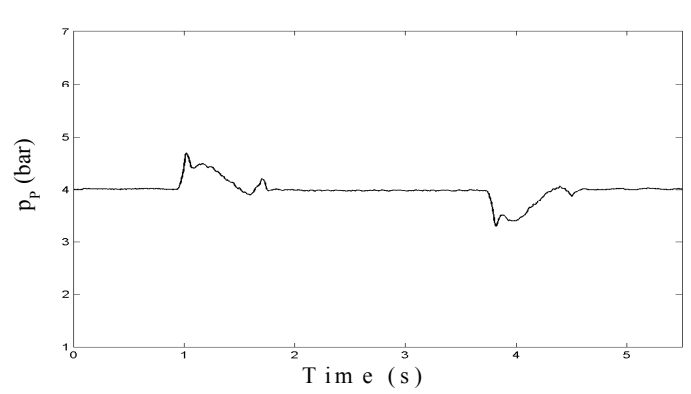

Fig. 9. Pressure $p_{P}$ (bar)

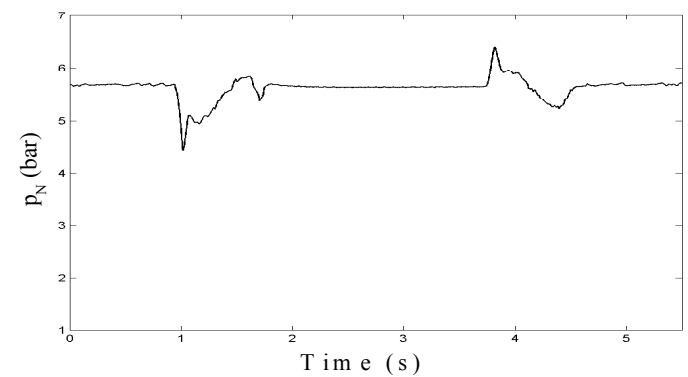

Fig. 10. Pressure $p_{N}$ (bar)

Considering Fig. 11 and Fig. 12, the control signals are smooth, which is a good property from an energetically efficient point of view. Indeed, when the control signal increases, supply energy is used and when the control signal decreases, the pneumatic energy approaches the exhaust. So the control signal oscillations leads to bad efficiency. 
Table 2

Experimental results in position

\begin{tabular}{c|cccc}
\hline $\begin{array}{c}\text { Control } \\
\text { strategy }\end{array}$ & $\begin{array}{c}\text { Maximum } \\
\text { position } \\
\text { error in dynamic } \\
\text { stage }\end{array}$ & $\begin{array}{c}\text { Mean standard } \\
\text { deviation } \\
\text { in dynamic stage }\end{array}$ & $\begin{array}{c}\text { Mean position } \\
\text { error in static } \\
\text { stage }\end{array}$ & $\begin{array}{c}\text { Mean standard } \\
\text { deviation } \\
\text { in static stage }\end{array}$ \\
\hline $\begin{array}{c}\text { Linear control } \\
\text { strategy }\end{array}$ & $4.26 \mathrm{~mm}$ & $135 \mu \mathrm{m}$ & $153 \mu \mathrm{m}$ & $40 \mu \mathrm{m}$ \\
$\begin{array}{c}\text { Nonlinear backstepping control } \\
\text { strategy }\end{array}$ & $1.62 \mathrm{~mm}$ & $80 \mu \mathrm{m}$ & $100 \mu \mathrm{m}$ & $40 \mu \mathrm{m}$ \\
\hline
\end{tabular}

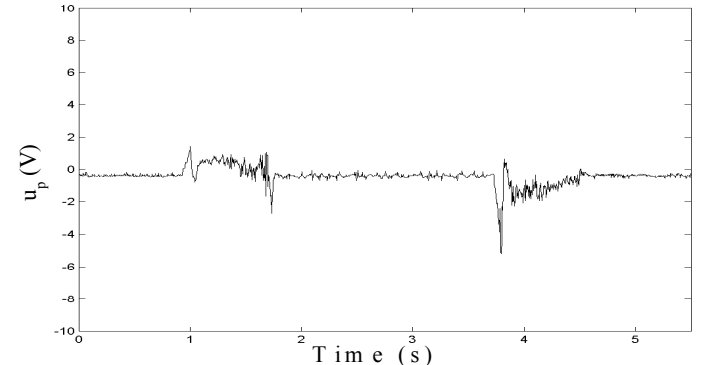

Fig. 11. Control input $u_{P}(\mathrm{~V})$

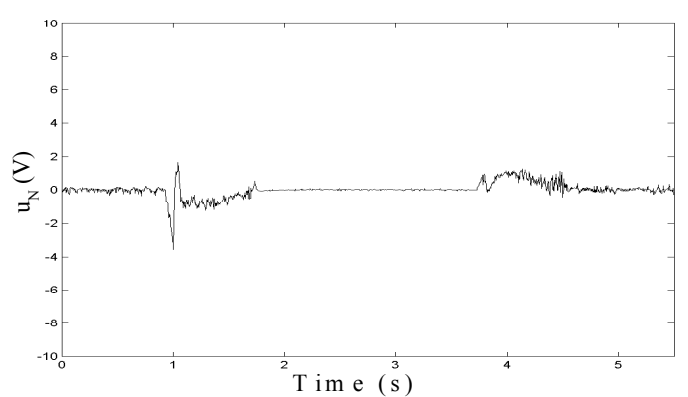

Fig. 12. Control input $u_{N}(\mathrm{~V})$

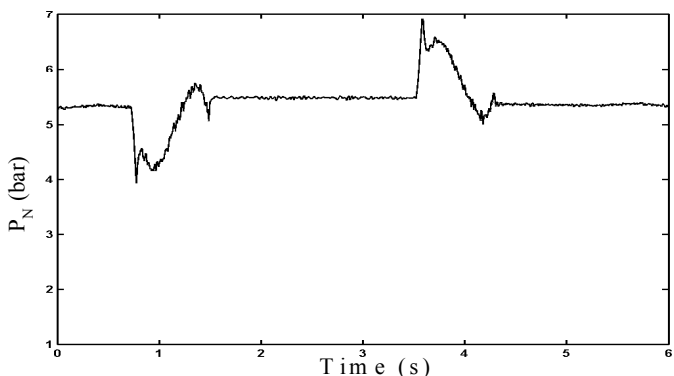

Fig. 16. Pressure $p_{N}$ (bar)

The control gains values are increased: $c_{1}=100$, $c_{2}=50, c_{3}=30, c_{4}=30$ and $\lambda=0.5$. As is shown in Fig. 17, the tracking position performances are better.

In steady state, the position error is about $100 \mu \mathrm{m}$ and the maximum position tracking error is about $1.62 \mathrm{~mm}$, which is about $0.65 \%$ of the total displacement.

A classical linear control law with scheduling gains, based on the local linearization of the nonlinear dynamics about a nominal operating point is proposed in (Brun et al., 1999a). The control law have been implemented on the same experimental set-up, in the same conditions. By using the same desired position (i.e. the maximum desired velocity is equal to 0.6 $\mathrm{m} / \mathrm{s}$ ), this algorithm is applied to the electropneumatic system. In this case, the maximum position error is about $4.26 \mathrm{~mm}$ and the mean position error in static stage is about $153 \mu \mathrm{m}$. So the best performances are obtained using backstepping controller in terms of position tracking. The standard deviation, mean and maximum position error are presented in table 2 for the backstepping control law and the classical linear control law. From table 2, it is clear that the proposed algorithm gives also the best results in term of mean standard deviation in dynamic stage.

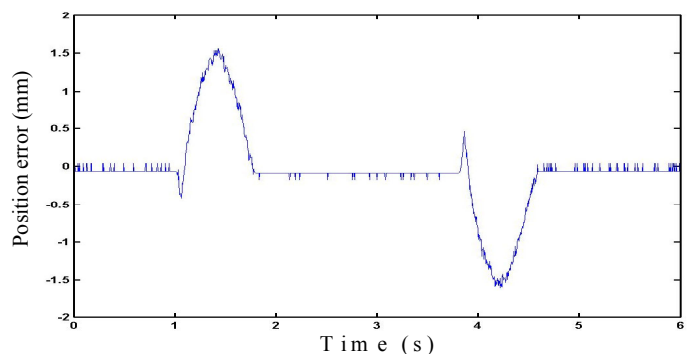

Fig. 17. Position error (mm)

The pressures are stabilized quickly (see Fig. 18 and Fig. 19). Indeed, it is important to note that the position and the two pressures reached equilibrium at the same time, i.e. the total equilibrium is achieved. With a classical linear control law, the mechanical equilibrium (position and velocity) is achieved but the pressure continues to evolve. In this case, sometimes the piston coming unstuck after a quasi-static stage (Brun et al., 1999b; Parnichkun \& Ngaecharoenkul, 2001),. So, with this controller, one can avoid this dangerous problem.

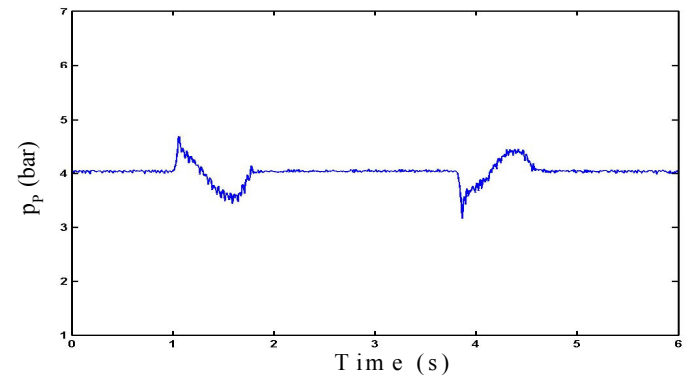

Fig. 18. Pressure $p_{p}$ (bar) 


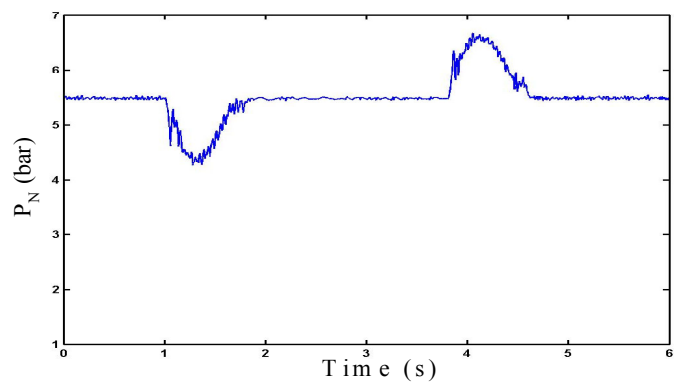

Fig. 19. Pressure $p_{N}$ (bar)

The control laws are those with some degree of oscillations (see Fig. 20 and Fig. 21). However, there is no noise that can be heard during the experiment which was not the case with sliding mode control. Indeed, sliding mode control is a attractive robust approach. It is believed that a robust controller can be derived based on rather little information of the system. This approach has been used in several works (Lin et al., 1998; Bouri, \& Thomasset, 2001). However, specific drawback presented by the sliding mode techniques is the chattering phenomenon which is generally perceived as motion, which oscillates around the sliding manifold. This phenomena is undesirable and seems decrease considerably the lifetime of some components (especially the servodistributor). So from this point of view, backstepping controllers seems more interesting that sliding mode controls.

Finally, it is important to note that experiment results are obtained without control signal saturation.

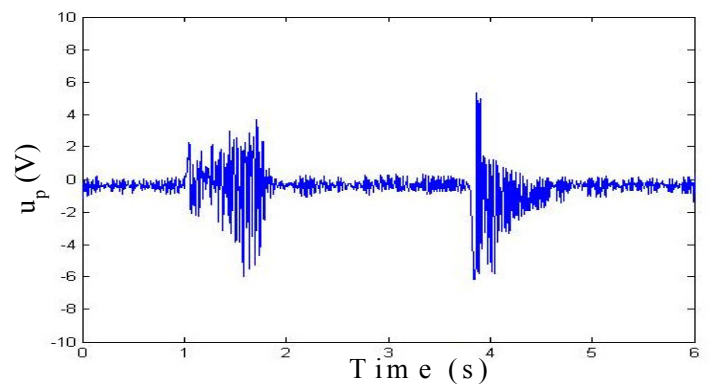

Fig. 20. Control input $u_{P}(V)$

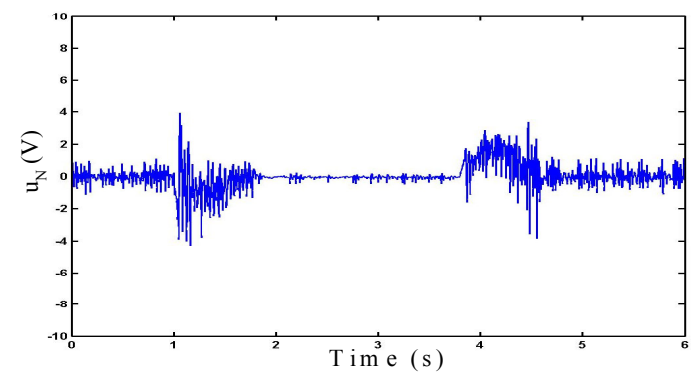

Fig. 21. Control input $u_{\mathrm{N}}(\mathrm{V})$

\section{Conclusion}

The novelty of this paper concerns the implementation of the well known strategy of control: backstepping. The difficulty concerns to extend the technique, today used for SISO system with strict feedback form model. Here the electropneumatic model is with two inputs and the strict feedback is not occurs. The advantages of applied this method in electropneumatic field can be summarizes in three essentials points:

- The control synthesis is developed tacking to account a non linear model of friction. This point is crucial to resolve a difficult problem in electropneumatic system: the stick-slip occurrence.

- In these results an appreciable improvement has been noted. The global stability of the closed loop system is proved

- The experiment implementation leads to better performances then linear classical control strategy in terms of precision in static and in dynamic stages. For this more sensors are necessary and the complexity to synthesis increases compare to classical linear strategy. But the most important for industrial is preserved: the simplicity to tune the control gains which regulate feedback errors in position, velocity and pressure in each chamber. So the results of this new control law summarized in table 3 were very interesting in regard of precedents one.

Table 3

Results synthesis.

\begin{tabular}{l|cc}
\hline & $\begin{array}{c}\text { Linear } \\
\text { control }\end{array}$ & $\begin{array}{c}\text { Backstepping } \\
\text { control }\end{array}$ \\
\hline Static error in position & + & ++ \\
Error in position tracking & + & ++ \\
Standard deviation & + & + \\
Stick-slip occurrence & -- & + \\
Number of sensors & 1 & 3 \\
Complexity to synthesis & + & -- \\
Complexity to tune & + & + \\
\hline
\end{tabular}

This study was lead in order to help the users of electropneumatic actuators to choose an appropriate strategy of control for fixed specifications.

Moreover the backstepping technique is a robust non linear control methodology and future works will prove the robustness of this approach in regards of environment variation (for example the load variation). But this first results proved the robustness in regards of difficult terms to identify, as mass flow leakage which is difficult to measured or friction force which its variations are important in this system. 


\section{References}

Armstrong-Helouvry, B., Dupont, P., \& Canudas de Wit, C., (1994). A survey of models, analysis tools and compensation methods for the control of machines with friction. Automatica, vol.30, pp. 1083-1138.

Belgharbi, M., Thomasset, D., Scavarda, S., \& Sesmat, S. (1999). Analytical model of the flow stage of a pneumatic servodistributor for simulation and nonlinear control. In the Sixth Scandinavian International Conference on Fluid Power, SICFP'99, Tampere, Finland, pp. 847-860.

Bouri, M., \& Thomasset, D. (2001). Sliding Control of an Electropneumatic Actuator Using an Integral switching Surface. IEEE Transaction on control systems technology. vol. $9 \mathrm{n}^{\circ} 2$, pp.368-375

Brun, X., Sesmat, S., Thomasset, D., \& Scavarda, S. (1999a). A comparative study between two control laws of an electropneumatic actuator. European Control Conference ECC'99 Karlsruhe, [CD Rom], reference F1000-5. 1999a.

Brun, X., Sesmat, S., Scavarda, S., \& Thomasset, D. (1999b). Simulation and experimental study of the partial equilibrium of an electropneumatic positioning system, cause of the sticking and restarting phenomenon. $4^{\text {th }}$ JHPS International Symposium on Fluid Power, Tokyo, Japan, pp. 125-130.

Brun, X., Thomasset, D., \& Bideaux, E. (2002). Influence of the process design on the control strategy: application in electropneumatic field. Control Engineering Practice, vol. 10, $\mathrm{n}^{\circ} 7$, pp.727-735.

Freeman, R.A., \& Kokotović, P. (1993). Design of 'softer' robust nonlinear control laws. Automatica, pp. 1425-1437.

Kanellakopoulos, I., Kokotović, P., \& Morse, A.S. (1991). Systematic design of adaptive controllers for feedback linearizable systems. IEEE Transactions on Automatic Control, vol. 36, pp. 1241-1253.

Khalil, H. (2001). Nonlinear Systems. Prentice-Hall, third edition, $750 \mathrm{p}$.

Kim, T.C., Rook, T.E. Singh, R. (2003). Effect of smoothening functions on the frequency response of an oscillator with clearance non-linearity. Journal of Sound and Vibration, vol. 263, pp. 665-678.

Kimura, T., Hara, S., Fujita, T., \& Kagawa, T. (1997). Feedback linearization for pneumatic actuator systems with static fiction. Control engineering practice. vol. 5, $\mathrm{n}^{\circ} 100, \mathrm{pp} .1385-$ 1394.

Krstić, M., Kanellakopoulos, I., \& Kokotović, P. (1995). Nonlinear and Adaptive Control Design. John Wiley \& Sons, 563 p.
Lee, H.K., Choi, G.S., Choi, G.H. (2002), A study on tracking position control of pneumatic actuators. Mechatronics. vol. 12, pp. 813-831.

Leine, R. I., Van Campen, D. H. and De kraker, A. (1998). Stick-Slip Vibrations Induced by Alternate Friction Models. Nonlinear Dynamics, vol. 16, pp. 41-54.

Mattei, M., (2001) Robust regulation of the air distribution into an arc heater. Journal of process control, vol. 11, pp. 285-297.

Parnichkun, M., \& Ngaecharoenkul, C., (2001) Kinematics control of a pneumatic system by hybrid fuzzy PID. Mechatronics. vol. 11, pp. 1001-1023.

Sesmat, S., \& Scavarda, S. (1996). Static characteristics of a three way servovalve. In $12^{\text {th }}$ Aachen Conference on Fluid Power Technology, Aachen, Germany, March 12-13, pp. 643-652.

Shearer, J.L. (1956). Study of pneumatic processes in the continuous control of motion with compressed air. Parts I and II. Trans. Am. Soc. Mech. Eng., vol. 78, pp. 233-249.

Shih, M.C. \& S., Tseng (1995), Identification and position control of a servo pneumatic cylinder. Control Engineering Practice Vol. 3, $\mathrm{n}^{\circ}$ 9, pp. 1285-1290

Tustin, A. (1947). The effect of backlash and speeddependent friction on the stability of closed-cycle control systems. Journal of the Institution of Electrical Engineers, vol. 94, n² A, pp 143-151.

Wang, J., Pu, J., \& Moore, P., (1999a). A practical control strategy for servo-pneumatic actuator systems. Control Engineering Practice, vol. 7, $\mathrm{n}^{\circ}$ 12, pp. 1483-1488.

Wang, J., Pu, J., \& Moore, P., (1999b). Accurate position control of servo pneumatic actuator systems: an application to food packaging. Control Engineering Practice. vol. 7, n 6, pp. 699-706. 